\title{
Espaço Físico da Escola Pública Goiana de Tempo Integral: dados e apontamentos
}

Valdeniza Lopes Barra'

'Universidade Federal de Goiás (UFG), Goiânia/GO - Brasil

RESUMO - Espaço Físico da Escola Pública Goiana de Tempo Integral: dados e apontamentos ${ }^{1}$. A ampliação da jornada escolar nas redes públicas de educação é apreendida em dados construídos a partir de base empírica advinda de pesquisa tipo survey realizada no estado de Goiás. O foco temático é o espaço físico que sedia a escola goiana de tempo integral, com recorte sobre os Anos Iniciais do Ensino Fundamental. Portanto os dados postos à análise se interessam pela escola cuja jornada foi ampliada e pretende pensá-la a partir de aspectos como: a) locais dentro e fora da escola onde são realizadas as atividades; b) cronologia de edificação dos prédios escolares onde estas escolas funcionam; c) ambientes escolares que receberam reformas ou adaptações; d) ambientes escolares que requerem reformas; e) ambientes escolares que precisam ser construídos.

Palavras-chave: Educação. Escola. Tempo. Espaço Físico Escolar. Goiás.

ABSTRACT - Physical Space Public School Goiana of Full-Time: data and notes. The extension of the school day in public education networks is seized on data constructed from empirical basis arising from research survey kind in the state of Goiás. The thematic focus is the physical space that houses the goiana school full-time, with clipping about Years Elementary School Initials. Therefore the data at analysis are interested in the school whose journey has been expanded and intends to think of it from such aspects as: a) places inside and outside the school where they are carried out; b) timing of construction of school buildings where these schools operate; c) school environments receiving reforms or adjustments; d) school environments that require reforms; e) school environments that need to be built. Keywords: Education. School. Time. School Physical Space. Goiás.

Educação \& Realidade, Porto Alegre, v. 42, n. 3, p. 1081-1101, jul./set. 2017. 1081 http://dx.doi.org/10.1590/2175-623660579 
Espaço Físico da Escola Pública Goiana de Tempo Integral

\section{Introdução}

O trabalho apresenta alguns dados de pesquisa survey realizada entre os anos de 2010 e 2013, com o título Educação Integral/Integrada e(m) Tempo Integral nas Escolas Públicas de Goiás. Propõe o exercício de pensá-los a partir dos respectivos conteúdos informados, naquilo que diz respeito às condições materiais nas quais se objetiva a escola goiana de tempo integral. O instrumento empregado na pesquisa foi um questionário composto de 32 questões de natureza majoritariamente quantitativa ${ }^{2}$. Este instrumento foi encaminhado para cerca de 150 municípios goianos, número definido após contato prévio telefônico ${ }^{3}$ com o objetivo de saber de cada Secretaria de Educação se aquela localidade tinha alguma experiência de ampliação da jornada escolar (escola de tempo integral), considerando-se os três universos constitutivos da rede pública de educação goiana, isto é, rede estadual, redes municipais e rede municipal de Goiânia. Obteve-se o retorno de 43 municípios da rede estadual e 27 municípios das redes municipais, isto é, 70 questionários respondidos que informavam a realização de alguma experiência de ampliação da jornada escolar na rede pública. Desse total, 10 municípios teriam experiências de ampliação da jornada escolar tanto na rede estadual, como nas redes municipais (Anápolis, Aragarças, Goiânia, Itaberaí, Jataí, Jussara, Mineiros, Rio Verde, Rubiataba, Vianópolis) ${ }^{4}$.

Constatou-se ter havido maior retorno de questionários dos municípios da rede estadual de educação, o que pode ser interpretado de duas maneiras: a) a rede estadual de educação organiza os municípios por meio das chamadas SRE (Superintendência Regional de Educação), o que determinou a logística de envio dos questionários, cabendo a cada SRE o envio do mesmo para os respectivos municípios a ela vinculados; b) se constitui como evidência de que ainda há no estado de Goiás, um número importante de municípios cuja primeira fase do Ensino Fundamental, encontra-se sob a orientação da Secretaria Estadual de Educação. A municipalização dos anos iniciais do Ensino Fundamental (EF) é prevista desde os anos $1990^{5}$, mas muitos municípios não dispõem de condição financeira para assumirem tal responsabilidade, cabendo ao estado "[...] definir, com os municípios, formas de colaboração na oferta do ensino fundamental” (Brasil, 1988, art. 10, II).

O menor retorno de questionários por parte das secretarias (redes municipais) pode ser atribuído a certa dispersão que as caracteriza. Embora, valha o registro de que a pesquisa identificou diálogos entre estas e a rede estadual, o que pode ser visto por meio de programas ou práticas comuns desenvolvidas em alguns municípios. Boa parte das secretarias (redes municipais) atua em condições muito precárias, entretanto há aquelas nas quais, a inexistência de filiação a alguma hierarquia direta não obsta sua efetivação como instância responsável pela política educacional de seu reduto.

Em 2009, a pesquisa Educação Integral/Integrada e(m) Tempo Integral: concepções e práticas na educação brasileira (Brasília, 2009) identificou 14 municípios goianos que informavam ter alguma experiência de ampliação da jornada escolar. O crescimento significativo no período

1082 Educação \& Realidade, Porto Alegre, v. 42, n. 3, p. 1081-1101, jul./set. 2017. 
recente é visível em escalas estadual (Figura 1) e municipal (Quadro 1). Vejamos o caso da rede municipal de Goiânia.

\section{Quadro 1 - Experiências de Ampliação da Jornada Escolar na Rede Municipal de Educação (RME) de Goiânia (2007-2013)}

\begin{tabular}{|c|l|}
\hline Período & \multicolumn{1}{|c|}{ Experiências de ampliação da jornada escolar } \\
\hline 2007 & Escola de Tempo Integral (03) \\
\hline 2008 & $\begin{array}{l}\text { Escola de Tempo Integral (06) } \\
\text { Programa Mais Educação (32) } \\
\text { Total: 38 }\end{array}$ \\
\hline 2013 & $\begin{array}{l}\text { Escola de Tempo Integral (22) } \\
\text { Programa Mais Educação (107) } \\
\text { Jornada Ampliada (05) } \\
\text { Total: 134 }\end{array}$ \\
\hline
\end{tabular}

Fonte: Relação das escolas de educação integral por ano na RME (DEFIA/SME Goiânia, 2013).

Os números vistos no quadro acima comprovam que a ampliação da jornada escolar (escola de tempo integral) emerge como tendência na rede municipal de Goiânia. A constatação também se dá na escala estadual. O mapa ${ }^{6}$, a seguir (Figura 1), revela que as experiências de ampliação da jornada escolar podem ser encontradas nas cinco mesorregiões do estado (Norte Goiano, Noroeste Goiano, Leste Goiano, Centro Goiano e Sul Goiano).

Figura 1 - Municípios com Experiências de Ampliação da Jornada Escolar nos Anos Iniciais do Ensino Fundamental em Goiás

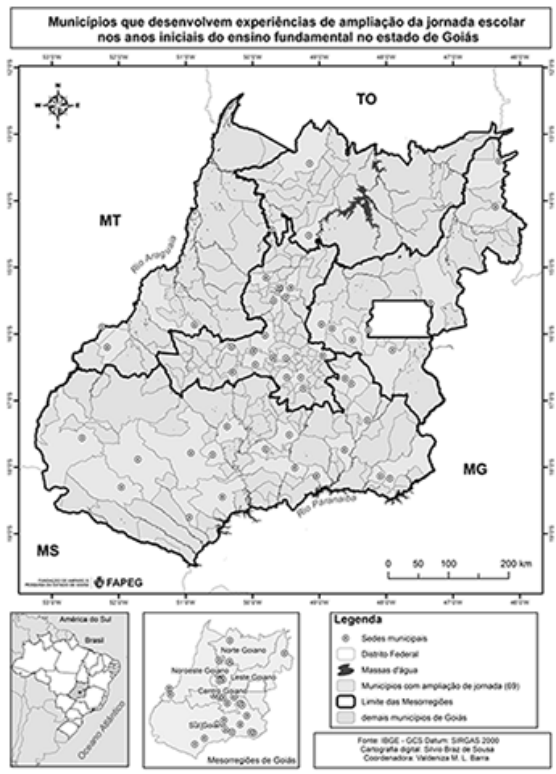

Fonte: Barra et al. (2016). 
Espaço Físico da Escola Pública Goiana de Tempo Integral

No mapa percebe-se que há concentração maior de experiências em municípios localizados no Centro Sul e Sul Goiano, regiões mais adensadas do ponto de vista populacional, o que traduz correspondência tácita com alguns preceitos inscritos no conjunto dos dispositivos de ampliação da jornada escolar, dentre os quais, o foco sobre situações de vulnerabilidade, risco, exclusão, trabalho infantil, exploração sexual e fragilização de vínculos, a que estão submetidos crianças, adolescentes e jovens (Brasil, 2007)7. Tais características são mais visíveis nas cidades mais populosas, onde a associação entre desemprego, pobreza, violência, etc. é adensada pelo número elevado de pessoas.

Esta constatação traz questões de relevo. Aqui serão exploradas algumas, dentre as quais, as que incidem sobre aspectos da rede física, com ênfase sobre a condição predial da escola de tempo integral dos anos iniciais do EF de Goiás: a) locais dentro e fora da escola onde são realizadas as atividades; b) cronologia dos prédios escolares; c) ambientes escolares que receberam reformas ou adaptações; d) ambientes escolares que requerem reformas; e) ambientes escolares que precisam ser construídos.

Discorrer sobre os cinco aspectos citados é exercício indissociável da tematização da escola contemporânea a partir de um eixo que aqui é relevante, o espaço físico no qual se objetiva a escola. Numa perspectiva sócio-histórica e, tendo como foco a realidade francesa, Guy Vincent, Bernard Lahire, Daniel Thin argumentam que a escola moderna ${ }^{8}$ se reveste da necessidade do espaço físico específico para a atividade escolar que seja "[...] distinto dos lugares onde se realizam as atividades sociais" (Vincent; Lahire; Thin, 2001, p. 13-15). Tal espaço específico deveria se relacionar com um tempo específico. Ali as crianças deveriam, pela via da sujeição e da obediência, incorporar regras impessoais típicas do processo civilizatório que visava, entre outros, a vulgarização da cultura escrita. Neste modelo ou forma escolar, o professor se constituiria como autoridade que detinha a competência específica garantida pelo diploma ou certificado ou por alguma competência mensurável. Alinhando-se a esta compreensão António Viñao Frago e Agustín Escolano (1998) expõem que o convencimento sobre a necessidade de um edifício próprio é parte da confluência de forças ou tendências que também incluem a especialização ou a profissionalização docente.

Da mesma maneira que para ser professor ou mestre não servia qualquer pessoa, tampouco qualquer edifício ou local servia para ser uma escola. O edifício escolar deveria ser configurado de um modo definido e próprio, independente de qualquer outro, ou em um espaço adequado para tal fim (Frago; Escolano, 1998, p. 73).

A trajetória histórica do lugar físico-arquitetônico da escola primária brasileira é identificada em diferentes momentos que caracterizariam as múltiplas temporalidades da escola primária brasileira: 1) séculos XVIII e XIX: escolas de improviso, 2) final do século XIX e início do século XX: escolas-monumento e 3) século XX: escolas funcionais (Faria Filho; Vidal, 2000, p. 20). Embora se tenha logrado o entendimen- 
to da necessidade de prédios para as mesmas, os significados de tais espaços continuam sendo objetos de luta (Faria Filho; Vidal, 2000).

Tomando de empréstimo a classificação de Faria Filho e Vidal (2000) pode-se dizer que a trajetória histórica do espaço físico da escola primária goiana saiu da condição de improviso para a de escola funcional, sendo mais difícil identificar a escola denominada monumen$t o^{9}$, aquela caracterizada por modelos arquitetônicos arrojados e, por diferentes razões, é um modelo que não se reproduz em série (Barra, 2013). Entretanto, cabe ressaltar que o valor da escola monumento está na materialidade que pretende traduzir a vontade cultural da sociedade de uma época. Na atualidade parece que improviso e funcionalidade se hibridizam. No início de 2007, chamava a atenção, a matéria jornalística que trazia a seguinte manchete em jornal goiano: Nossa escola de tempo integral não é feita de prédios, mas de pessoas.

O problema é que muita gente imaginou que iríamos apresentar a escola de tempo integral dentro da expectativa convencional, que significa construção de grandes estruturas físicas, com quadras, refeitórios, teatros. Qual não foi a surpresa e a decepção de alguns quando apresentamos um projeto de educação em tempo integral diferente, calcado num projeto pedagógico ousado, em que as pessoas são mais importantes do que os prédios. É claro que a infraestrutura é importante, mas o ser humano é muito mais importante. O projeto pedagógico e a qualificação de professores nele envolvidos é muito mais importante do que começar a escola em tempo integral pelo prédio. No passado, as experiências que começaram com a construção de grandes prédios não deram certo (Severino, 2007, p. 18)

A entrevista tinha a finalidade de expor os processos de implantação da escola de tempo integral na rede estadual de Goiás - o aproveitamento da estrutura existente, contrapondo-o com experiências como os CIEPs (Centros Integrados de Educação Pública) do Rio de Janeiro, onde nos anos 1980 e 1990, se construiu estruturas extraordinárias, cerca de 500 unidades prediais escolares com concepções administrativa e pedagógica próprias e que foram descontinuadas nas gestões políticas sucessivas (Cavaliere, 2002). O conteúdo da entrevista acima, ao revelar o modo de implantar a ampliação da jornada escolar em Goiás, também corrobora os dados da pesquisa que evidenciou que os quase $100 \%$ de municípios pesquisados desenvolvem as suas experiências de ampliação da jornada escolar em escolas cuja edificação predial é anterior à política de ampliação do tempo escolar. O uso de prédios já existentes revela uma estratégia de racionalização e de otimização de recursos e da rede física existente. Esta estratégia é evidenciada pela pesquisa e aparece na escola, visceralmente combinada com táticas ${ }^{10}$, de alternativas cotidianas para equacionar as novas demandas da escola de tempo integral às condições físicas reais e os constrangimentos aí instalados.

Na atualidade o Mais Educação, programa do governo federal, cumpre o papel de indutor da política de ampliação da jornada esco- 
lar em todo o país, sendo o responsável hegemônico pela ampliação da jornada escolar na cidade de Goiânia, capital de Goiás. No período de cinco anos (2008-2013), elevou o número de escolas com experiências de ampliação da jornada de 32 para 107, o que corresponde ao aumento de $300 \%$ (Quadro 1). Ao perspectivar o tema em escala estadual, tal como se propõe o quadro a seguir (Quadro 2), se vê que este programa é preponderante na capital Goiânia e nos dois outros universos pesquisados (redes municipais e rede estadual).

\section{Quadro 2 - Experiências de Ampliação da Jornada Escolar nos} Anos Iniciais do $\mathbf{E F}^{11}$

\begin{tabular}{|l|l|l|}
\hline \multicolumn{1}{|c|}{$\begin{array}{c}\text { Rede municipal de } \\
\text { educação de Goiânia }\end{array}$} & \multicolumn{1}{|c|}{ Redes municipais } & \multicolumn{1}{c|}{ Rede estadual } \\
\hline -Mais Educação (76\%) & -Mais Educação (80,7\%) & -Escola de tempo integral \\
-Escola de tempo integral & -Escola de tempo integral \\
$(38,4 \%)$ & -Mais Educação (41\%) \\
(17\%) & -Reforço escolar no contra & -Turno de ampliação da \\
-Jornada ampliada (7\%) & turno (34,6\%) & aprendizagem (35,8\%). \\
\hline
\end{tabular}

Fonte: Barra et al. (2016).

Este programa corresponde, em números médios, a $66 \%$ das experiências de ampliação da jornada escolar realizadas no estado de Goiás. Evidencia-se assim que este programa é o responsável hegemônico pela ampliação da jornada nas três escalas: municipal (Quadro 1), estadual (Figura 1, Quadro 2), nacional (Quadro 3).

Quadro3-Número de Escolas como Mais Educação no Brasil (2008-2011)

\begin{tabular}{|c|c|}
\hline Ano & No de escolas $^{2008}$ \\
2009 & 1.380 \\
2010 & 5.004 \\
2011 & 10.026 \\
\hline
\end{tabular}

Fonte: Moll (2012).

O programa Mais Educação (Brasil, 2007) é importante responsável pela capilarização da ampliação da jornada escolar no país, além de compor um conjunto de ações discursivas e práticas que redimensionam os sentidos do par tempo e espaço escolar a partir das novas funções educativas, movimento consoante à reconfiguração do tempo escolar, ou das políticas que intentam pela escola de tempo integral. Ana Cavaliere (2014) adverte que este programa, ao prescindir da construção de novos prédios, valendo-se de espaços físicos da comunidade, tanto difunde como contribui para naturalizar as condições precárias da educação brasileira (Cavaliere, 2014).

O Plano Nacional de Educação (Brasil, 2001) ao mencionar a escola de tempo integral, elenca diferentes metas para adequação e ampliação do espaço físico escolar. Todas as investidas do referido documento acerca de tal questão tendem a valorizar e consolidar o espaço físico da escola como o espaço que deve ser aperfeiçoado mediante o redimen-

1086 Educação \& Realidade, Porto Alegre, v. 42, n. 3, p. 1081-1101, jul./set. 2017. 
sionamento da jornada escolar, tanto quanto com a devida provisão de equipamentos necessários às atividades pedagógicas ali desenvolvidas.

A partir de 2007 nota-se um conjunto de dispositivos legais de matriz federal que orientam a abertura da escola para o seu entorno. A Portaria Interministerial no 17, de 24 abril de 2007 (Brasil, 2007, art. $8^{\circ}$. incisos I e III), contrabalanceia a ampliação do “[...] tempo e dos espaços educativos" e apela para a direção de "[...] mobilizar e estimular a comunidade local para a oferta de espaços”. O Decreto n 7.083, de 27 de janeiro de 2010 (Brasil, 2010, art. 1, § $3^{\circ}$ ) instruirá sobre tal matéria da seguinte maneira:

[...] as atividades poderão ser desenvolvidas dentro do espaço escolar, de acordo com a disponibilidade da escola, ou fora dele sob orientação pedagógica da escola, mediante o uso dos equipamentos públicos e do estabelecimento de parcerias com órgãos ou instituições locais.

Também se verifica no Plano Nacional de Educação (Brasil, 2014) o alinhamento com o discurso que conduz a escola para fora da escola. A um só tempo em que propõe um "[...] programa nacional de ampliação e reestruturação das escolas públicas” (Brasil, 2014, estratégia 6.2), há o apelo em "[...] fomentar a articulação da escola com os diferentes espaços educativos e equipamentos públicos como centros comunitários, bibliotecas, praças, parques, museus, teatros e cinema” (Brasil, 2014, estratégia 6.2).

A pesquisa identificou que apenas a rede municipal de Aparecida de Goiânia teria construído quatro novas escolas $(2004,2011,2012)$ visando à ampliação da jornada escolar (Escola de tempo integral). Na rede estadual de educação, houve dois municípios que receberam novos prédios escolares, sendo Cachoeira Alta (2004) e Santa Helena de Goiás (2008), mas não se pode afirmar relação direta com a ampliação da jornada escolar. Já a preocupação quanto à reforma ou adaptação de ambientes dos prédios escolares existentes aparece nas três redes pesquisadas, revelando que algumas das escolas representadas por aqueles universos sofreram algum tipo de reforma ou adaptação: rede municipal de Goiânia (79,8\%); redes municipais (57,6\%); rede estadual (57\%). O Quadro 4 a seguir sintetiza a história predial das escolas que sediam ampliação da jornada escolar no estado. 
Espaço Físico da Escola Pública Goiana de Tempo Integral

\section{Quadro 4 - Cronologia dos Prédios Escolares Edificados em Goiás e Onde Funcionam Escolas Públicas de Tempo Integral dos Anos Iniciais do Ensino Fundamental ${ }^{12}$}

\begin{tabular}{|c|c|c|c|c|c|c|c|}
\hline \multicolumn{8}{|c|}{ Rede Municipal de Goiânia } \\
\hline $\begin{array}{c}\text { Anos } \\
1930\end{array}$ & $\begin{array}{l}\text { Anos } \\
1940\end{array}$ & Anos 1950 & $\begin{array}{c}\text { Anos } \\
1960\end{array}$ & $\begin{array}{c}\text { Anos } \\
1970\end{array}$ & $\begin{array}{c}\text { Anos } \\
1980\end{array}$ & $\begin{array}{l}\text { Anos } \\
1990\end{array}$ & $\begin{array}{c}\text { Desde } \\
2000\end{array}$ \\
\hline- & - & 04 & 20 & 20 & 19 & 28 & 05 \\
\hline \multicolumn{8}{|c|}{ Redes Municipais } \\
\hline $\begin{array}{l}\text { Anos } \\
1930\end{array}$ & $\begin{array}{c}\text { Anos } \\
1940 \\
\end{array}$ & Anos 1950 & $\begin{array}{c}\text { Anos } \\
1960 \\
\end{array}$ & $\begin{array}{l}\text { Anos } \\
1970 \\
\end{array}$ & $\begin{array}{c}\text { Anos } \\
1980 \\
\end{array}$ & $\begin{array}{l}\text { Anos } \\
1990 \\
\end{array}$ & $\begin{array}{c}\text { Desde } \\
2000 \\
\end{array}$ \\
\hline--- & --- & Anápolis & Jataí & $\begin{array}{l}\text { Alexânia, } \\
\text { Firmi- } \\
\text { nópolis, } \\
\text { Formosa, } \\
\text { Luziânia, } \\
\text { Rio Ver- } \\
\text { de, Ru- } \\
\text { biataba, } \\
\text { Serranó- } \\
\text { polis. }\end{array}$ & 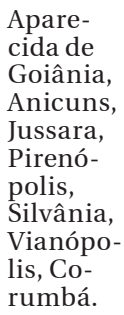 & $\begin{array}{l}\text { Itaberaí. } \\
\text { Santa } \\
\text { Isabel, } \\
\text { Rialma, } \\
\text { São Do- } \\
\text { mingos. }\end{array}$ & $\begin{array}{l}\text { Acreúna, } \\
\text { Ara- } \\
\text { garças, } \\
\text { Sancler- } \\
\text { lândia }\end{array}$ \\
\hline \multicolumn{8}{|c|}{ Rede Estadual } \\
\hline $\begin{array}{l}\text { Anos } \\
1930\end{array}$ & $\begin{array}{c}\text { Anos } \\
1940\end{array}$ & Anos 1950 & $\begin{array}{l}\text { Anos } \\
1960\end{array}$ & $\begin{array}{c}\text { Anos } \\
1970\end{array}$ & $\begin{array}{l}\text { Anos } \\
1980\end{array}$ & $\begin{array}{c}\text { Anos } \\
1990\end{array}$ & $\begin{array}{c}\text { Desde } \\
2000\end{array}$ \\
\hline $\begin{array}{l}\text { Silvânia } \\
\text { e Goian- } \\
\text { dira. }\end{array}$ & $\begin{array}{l}\text { Minei- } \\
\text { ros, } \\
\text { Itapaci, } \\
\text { Goiânia, } \\
\text { Pontali- } \\
\text { na. }\end{array}$ & $\begin{array}{l}\text { Jataí, Ria- } \\
\text { nópolis, } \\
\text { Orizona, } \\
\text { Rubiata- } \\
\text { ba, Inhu- } \\
\text { mas. }\end{array}$ & $\begin{array}{l}\text { Itumbia- } \\
\text { ra, Ceres, } \\
\text { Uruana, } \\
\text { Vianópo- } \\
\text { lis, Goia- } \\
\text { tuba, } \\
\text { Catalão, } \\
\text { Morri- } \\
\text { nhos, Po- } \\
\text { rangatu, } \\
\text { Anápolis, } \\
\text { Itauçu, } \\
\text { Quirinó- } \\
\text { polis. }\end{array}$ & $\begin{array}{l}\text { Itaberaí, } \\
\text { Vicenti- } \\
\text { nópolis, } \\
\text { Ouvidor, } \\
\text { Pilar de } \\
\text { Goiás, } \\
\text { Santa } \\
\text { Terezi- } \\
\text { nha, Rio } \\
\text { Verde, } \\
\text { Jussara, } \\
\text { Uruaçu. }\end{array}$ & $\begin{array}{l}\text { Ameri- } \\
\text { cano do } \\
\text { Brasil, } \\
\text { Mar- } \\
\text { zagão, } \\
\text { Caldas } \\
\text { Novas, } \\
\text { Posse. }\end{array}$ & --- & --- \\
\hline
\end{tabular}

Fonte: Barra et al. (2016).

O quadro acima (Quadro 4) é virtuoso quando pretende datar a condição predial das escolas goianas de tempo integral. Mas é mais que isso. Permite compreender o movimento dos Anos Iniciais do EF nas redes públicas do estado de Goiás, o que parece justificar uma breve digressão histórica. Até os anos 1920, os registros demonstram que, salvo uma ou outra exceção, o lugar da escola primária goiana se restringia à locação de algum prédio que teria sido edificado para outra finalidade, em geral espaços domésticos (Barra, 2013). Exemplo é o relato do diretor do grupo escolar da capital goiana que se dirigia à Secretaria de Interior e Justiça de Goiás em 1924 em tom de lamento sobre as condições do referido estabelecimento escolar:

1088 Educação \& Realidade, Porto Alegre, v. 42, n. 3, p. 1081-1101, jul./set. 2017. 


\begin{abstract}
[...] passarem as crianças, sob um calor intenso, quatro horas seguidas em salas sem ar e sem luz suficiente e sem que pudessem gozar do intervalo de recreio pela inexistência de pátio adequado [...] as salas de aula dos meninos se localizavam nos aposentos outrora reservados às despensas da casa e contíguos à cozinha da residência próxima, donde escapavam ondas de fumaça que, penetrando na sala de aula, tiravam a respiração normal das crianças (Silva, 1975, p. 235).
\end{abstract}

No cenário nacional os anos compreendidos pela primeira e segunda república foram palco do entusiasmo educacional e do otimismo pedagógico (Nagle, 1974). O entusiasmo de matiz republicano do final do século XIX tinha vocação quantitativa e pretendia a expansão da escola como forma de garantir que a alfabetização tivesse o maior alcance possível. Esse movimento resultará e se misturará ao otimismo pedagógico que, influenciado pelo escolanovismo dará um tom qualitativo, notado na defesa de uma escola mais aprimorada nos aspectos didático-pedagógicos. A reforma paulista dos anos 1920 propunha que o mesmo prédio escolar atendesse, num só dia, a três turnos distintos. Para Ana Cavaliere (2003, p. 43), a experiência histórica paulista é emblemática da "[...] antagonização entre a possibilidade da ampliação quantitativa e a garantia da qualidade", dilema que atravessou o século XX.

Parece razoável admitir que em Goiás uma das expressões de eco deste movimento nacional tenha sido a construção dos primeiros prédios escolares edificados para a finalidade escolar nos anos $1930^{13}$. Em conformidade com os dados evidenciados pela pesquisa, pode-se afirmar que serão os anos correspondentes ao governo militar (1960, 1970 e 1980) aqueles que mais edificarão prédios escolares no estado, o que em alguma medida, pode ser compreendido como uma pista que indica a demanda por estudos, mas que também constitui indício de que esta ideologia planejava o papel da escola em face de seus intentos, tendo em vista que este período histórico detinha forte ao apelo econômico na direção da industrialização (Saviani, 2008). Uma vista transversal sobre o quadro (Quadro 4) também aponta o movimento da municipalização do ensino primário, perceptível no movimento gradativo das municipalidades que assumiriam a escola primária. Da primeira à segunda república nota-se que o ensino primário goiano estava no cruzamento dado pela manutenção do município e pela inspeção do estado, uma reunião de forças que se traduzia na cisão de uma escola desprovida de endereço fixo (prédio escolar) (Barra, 2013).

A pesquisa sobre a ampliação da jornada na escola goiana atual se foca nos Anos Iniciais do EF, e mostra que em Goiás, há presença importante do estado na condução da escola primária, especialmente nos municípios do interior do estado. Também cabe destacar que a maior parte dos prédios que sediam a primeira fase do EF, também oferta a segunda fase e, em muitos casos, também o Ensino Médio. Ou seja, o prédio edificado para ser escola, em geral, não foi planejado para uma etapa específica da formação escolar (infância, adolescência, jovem, adulto). Assim o prédio escolar é um espaço de aparente rigidez, para não dizer, limitada arquitetura, mas de grande lassidão nos usos. A isto talvez se chame funcionalidade.

Educação \& Realidade, Porto Alegre, v. 42, n. 3, p. 1081-1101, jul./set. 2017. 
Espaço Físico da Escola Pública Goiana de Tempo Integral

A acomodação de diferentes faixas etárias no mesmo prédio, prática cuja idade se confunde com a criação da escola primária brasileira, certamente impõe arranjos ou adaptação de práticas e de uma rigidez dos corpos. Contudo, esta questão parece não produzir visibilidade ou intervenções no seu entorno. Mas a ampliação do tempo escolar insta a escola a mexer em linhas estruturais da sua organização. Assim sendo, também alavanca a discussão sobre qual seja o estatuto desta territorialidade, o espaço escolar. É que a extensão da jornada (tempo) dá a ver o espaço. E aí vale a interlocução com Norbert Elias (1998), para quem a mensuração do tempo tem relação direta com determinadas sequências que servem como pontos de referência e meios de comparação, além de serem dotadas de símbolos reguladores e cognitivos. Trata-se daquilo que o autor chama de reaparecimento regular - sucessão ou recorrência - de certos modelos sequenciais (Elias, 1998). Está se tratando da ampliação da jornada diária escolar, quer isto dizer que, estamos falando do conjunto ampliado das atividades previstas que podem ser observadas na sucessão ou recorrência dos dias: café - aula - recreio oficina - almoço - oficina - recreio - aula. Ampliou-se o tempo porque foi aumentado o repertório de ações num modelo onde há recorrência e sucessão, haja vista a simulação do horário escolar diário, correspondente de um modelo sequencial de ações.

Esta sucessão temporal insta pela dimensão física do espaço. Em se tratando da ampliação da jornada se verifica que o apelo a que a escola se comunique com o seu entorno não se origina de uma proposta pedagógica ou multissetorial cuja matriz seja um projeto consistente de formação humana. Parece ser esta uma alternativa que combina a necessidade social de viabilizar a escola de tempo integral a partir da escola existente. Valeria indagar, à moda de António Viñao Frago e Agustín Escolano (1998) se esta é uma mudança do continente, do conteúdo ou de ambos? (Frago; Escolano, 1998). Sobre a relação entre o dentro e o fora da escola a pesquisa identificou nos três universos respondentes que a grande maioria das atividades associadas à ampliação da jornada ocorre no interior da própria escola: 96,4\% (rede municipal de Goiânia), 92,9\% (redes municipais), 81,4\% (rede estadual). Os três espaços indicados nas primeiras posições foram os listados no quadro a seguir (Quadro 5).

Quadro 5 - Locais (Dentro e Fora da Escola) das Atividades de Ampliação da Jornada Escolar em Goiás

\begin{tabular}{|l|l|l|}
\hline & \multicolumn{1}{|c|}{ Dentro $\mathbf{( 9 0 , 2 \% )}$} & \multicolumn{1}{c|}{ Fora $\mathbf{( 9 , 8 \% )}$} \\
\hline $\begin{array}{l}\text { Rede Municipal de } \\
\text { Goiânia }\end{array}$ & Sala de aula, pátio, quadra. & $\begin{array}{l}\text { Campo de futebol, quadra, } \\
\text { clube. }\end{array}$ \\
\hline Redes municipais & $\begin{array}{l}\text { Sala de aula, pátio, labo- } \\
\text { ratório. }\end{array}$ & $\begin{array}{l}\text { Campo de futebol, clube, } \\
\text { igreja. }\end{array}$ \\
\hline Rede estadual & $\begin{array}{l}\text { Sala de aula, pátio, labo- } \\
\text { ratório. }\end{array}$ & $\begin{array}{l}\text { Praça pública/parque, } \\
\text { campo de futebol, clube. }\end{array}$ \\
\hline
\end{tabular}

Fonte: Barra et al. (2016).

A média geral das atividades realizadas dentro da escola nos três universos pesquisados é de 90,2\%, enquanto 9,8 \% das atividades das 
escolas goianas de tempo integral se dão fora da escola. Os espaços procurados fora da escola tendem a indicar que a escola busca no espaço de fora aquilo que supostamente devesse estar dentro da escola, isto é, espaços que comportem práticas com o corpo, sejam elas esportivas ou não. Mas no conjunto, o que se evidencia é a resistência das escolas públicas de Goiás em ceder ao apelo para o uso de equipamentos públicos de seu entorno, prevalecendo o emprego das dependências do interior da escola. O que pode ser explicado de diferentes maneiras. Estas incluem as dificuldades de locomoção dos alunos até os respectivos espaços (quando estes existem), a ausência de espaços públicos afins às atividades nos municípios do interior. A pesquisa constata a permanência no reduto interno da escola, mesmo quando a escola carece de espaços estruturais (salas, quadra, refeitório) nas suas dependências internas. Parece subjazer o entendimento de que a escola insiste em ser escola e a inscrição espacial é um dado substantivo no estatuto desta instituição. Lígia Martha Coelho, em situação parecida vista no Rio de Janeiro, apresenta a seguinte compreensão:

\begin{abstract}
[...] é preciso refletir sobre essa busca de parcerias como 'complemento' à ausência de espaço nas instituições formais de ensino. Se o propósito do município, com a experiência, for o de construir também uma educação integral, que tenha como fundamento uma formação mais completa para o aluno, o espaço apropriado para a realização dessas atividades formativas não pode ser complemento; deve sim, se constituir como pressuposto político-pedagógico para tal. Dessa forma, depender de parcerias que acontecem 'por tempo determinado' é estratégia que foge a essa concepção (Coelho et al., 2012, p. 64).
\end{abstract}

Compreende-se, portanto, que a busca de espaços externos à escola deve ser uma opção pedagógica da escola e não uma consequência das restrições de suas dependências interiores. Do contrário se estará atestando a edificação interrompida de edifícios escolares e a provisoriedade vitalícia de instalações escolares precárias.

Os locais mais empregados no interior da escola são a sala de aula, o laboratório e o pátio. A sala de aula e o pátio parecem ser aquelas dependências encontradas na grande maioria dos prédios escolares, mesmo os mais rudimentares. Talvez porque se tratem de espaços que dão conta de funções matriciais no trato com os alunos: a função de ensino, o movimento do corpo e da prática de socialização. A referência importante do uso do laboratório como ambiente interno da escola pode indicar, no caso da rede estadual, ressonância da "[...] matriz de referência para implantação das escolas de tempo integral" que prevê atividades práticas nos laboratórios de informática, ciências e línguas (Goiás, 2007, p. 26). Nos casos da rede municipal de Goiânia e das redes municipais de Goiás, a alta incidência do laboratório também pode ser referência ao laboratório de informática, espaço físico relativamente disseminado nas escolas atuais, apesar das recorrentes queixas da falta de manutenção e de falhas na conexão com a internet. 
Espaço Físico da Escola Pública Goiana de Tempo Integral

Já os espaços fora da escola relacionados nas respostas da pesquisa parecem apontar pela carência interna de espaços para atividades coletivas na escola de natureza esportiva, lúdica e também social, haja vista a necessidade de práticas esportivas, organização de reuniões, apresentação de peças teatrais, etc. O Mais Educação é a experiência que mais conversa com lado de fora da escola, cumprindo assim os desígnios estabelecidos pela sua criação ${ }^{14}$. Suas atividades envolvem gama variada de espaços de origem pública e privada, laica e religiosa, dentre as quais se incluem - por ordem - quadra, clube, circo, museu, shopping, ONG (Organização Não Governamental), etc.

Por oposição ou pela sua especificidade, vale destacar que a totalidade das atividades da Escola de tempo integral (rede municipal de Goiânia) e a grande maioria das atividades de Reforço escolar no contraturno (redes municipais e rede estadual) ocorrem no interior da escola, endossando assim, o entendimento de que essas têm foco na dimensão pedagógica, fazendo remissão direta com a especificidade escolar e, talvez por isto, devam ter lugar dentro da escola.

Partindo-se do entendimento de que a ampliação da jornada escolar possui uma dimensão social e cultural de relevo, se reconhece que os ambientes físicos que possuem relação mais direta com a ampliação da jornada escolar sejam: refeitório, sala (para oficinas), cozinha, sala de repouso, banheiros com vestiários. Isto porque tais espaços traduzem funções como o preparo e a prática das refeições, a necessidade de descanso, de higiene, etc. No intento de pensar as novas funções da escola e visualizá-la pelo lado de dentro a pesquisa indagou sobre reformas e adaptações realizadas e/ou necessárias, além de ambientes a serem construídos com vistas à melhor acomodação e desenvolvimento das atividades associadas à ampliação da jornada escolar.

Os dados obtidos estão dispostos nos três quadros a seguir (Quadro 6, Quadro 7 e Quadro 8) e dão a ver especificidades e semelhanças junto aos três universos pesquisados.

Quadro 6 - Ambientes Escolares que Sofreram Reformas ou Adaptações para a Ampliação da Jornada

\begin{tabular}{|c|c|c|}
\hline $\begin{array}{c}\text { Rede Municipal de } \\
\text { Goiânia }\end{array}$ & Redes municipais & Rede estadual \\
\hline $\begin{array}{l}\left.1^{\circ}\right) \text { construção de quiosque; } \\
\left.2^{\circ}\right) \text { rampas de acesso; } 3 \text { ) } \\
\text { tendas; } 4^{\circ} \text { ) construção de } \\
\text { bancos e mesas de cimen- } \\
\text { to; } 5^{\circ} \text { ) banheiros/ sala de } \\
\text { aula / pequenas adapta- } \\
\text { ções na estrutura física; } \\
\left.6^{\circ}\right) \text { construção de sala para } \\
\text { informática. Outros: re- } \\
\text { forma geral, adaptação ou } \\
\text { ampliação de cozinhas }\end{array}$ & $\begin{array}{l}\left.1^{\circ}\right) \text { refeitório/sala para } \\
\text { oficinas; } 2^{\circ} \text { ) banheiros/ } \\
\text { pátio com cobertura/ } \\
\text { salas de aula; } 3^{\circ} \text { ) quadras/ } \\
\text { pinturas. Também hou- } \\
\text { ve indicações de troca } \\
\text { de portas, adaptação de } \\
\text { rampas e banheiros para } \\
\text { portadores de necessida- } \\
\text { des educativas especiais. } \\
\text { Um município informou } \\
\text { a construção de uma pis- } \\
\text { cina, outro mencionou a } \\
\text { construção de quadra com } \\
\text { cobertura e cimentada, } \\
\text { dentre outros. }\end{array}$ & $\begin{array}{l}1^{\circ} \text { ) reforma do forro ou } \\
\text { telhado; } 2^{\circ} \text { ) refeitório/ } \\
\text { banheiros; } 3^{\circ} \text { ) quadra/ } \\
\text { salas de aula/ laboratórios } \\
\text { (informática, ciências); } 4^{\circ} \text { ) } \\
\text { pintura. } \\
\text { Outros: vestiários, fiação } \\
\text { elétrica, rampas, despensa, } \\
\text { cozinha, pátio, biblioteca, } \\
\text { muro, parte hidráulica, } \\
\text { cobertura para corredor } \\
\text { onde funciona refeitório, } \\
\text { dentre outros. }\end{array}$ \\
\hline
\end{tabular}

Fonte: Barra et al. (2016). 
O Quadro 6 reúne dados de reformas e/ou adaptações do espaço físico vistas nos três universos pesquisados, cumprindo uma função de produzir uma visão panorâmica do tema. Contudo, no afã de compreender melhor as práticas de reforma ou adaptação, optou-se por interpretar separadamente os dados de cada universo pesquisado (rede municipal de Goiânia, rede estadual, redes municipais).

No caso da rede municipal de Goiânia, os ambientes adaptados se destacam. São pela ordem: tendas, quiosques e mesas com bancos de cimento. Esses ambientes parecem revelar ao menos dois temas: improvisação e baixo custo. Tratam-se de alternativas (tendas e quiosques) e equipamentos (bancos e mesas de cimento) que são menos onerosas e dotadas da capacidade de acomodar diferentes atividades que supõem pequenos coletivos de alunos, conseguindo assim, dar respostas imediatas para as novas demandas postas para a escola. Ressalve-se que quiosques e tendas, encontrados na capital, são equipamentos artificiosos que se primam pelo uso diverso. O que se distingue de rampas de acesso, estas carregam o específico da sua função e são recorrentes nos três universos pesquisados. Cabe observar, entretanto que, o sentido da construção de rampas na escola não se associa diretamente à ampliação da jornada escolar, é uma demanda da generalidade da escola.

A rede estadual chama atenção pelo conjunto híbrido de reformas realizadas no qual se identifica itens como reforma do forro, reforma do telhado, pintura, fiação elétrica, muro, além de cobertura piso cimentado para a quadra. Essas reformas são combinadas com reformas de banheiros, salas de aula e adaptações que incluem cobertura para o corredor que atende à função de refeitório. Serviços assim, de hidráulica e elétrica, pintura e reforma do telhado, são demandados por qualquer estrutura predial, são da rubrica da manutenção.

Por sua vez, os ambientes reformados nas redes municipais compõem o conjunto que, em tese, mais as aproximaria das novas demandas da escola de jornada ampliada: refeitório, salas para oficinas, quadras, pátios, etc. No conjunto dos três universos, se distinguem os modos de arranjar o espaço físico escolar em cada rede de ensino. Há a cobertura para o corredor (rede estadual) e há a tenda ou o quiosque (rede municipal de Goiânia). A função parece comum. Pretende-se dar conta de condição física minimamente razoável com a função requerida pela prática da refeição dentro do espaço escolar.

O quadro a seguir (Quadro 7) traz dados que, à primeira vista, parecem se confundir com o teor do quadro anterior, mas são distintos. Enquanto aquele (Quadro 6) expunha reformas realizadas como forma de preparação do prédio escolar para a ampliação da jornada, o Quadro 7 relaciona os ambientes escolares que requerem reformas nas escolas que desenvolvem experiências de ampliação da jornada escolar. Perguntas interessadas em reformas realizadas e reformas necessárias à escola cumprem um papel central quando se persegue o entendimento da relação entre espaço e tempo escolar na escola de tempo integral. Suspeita-se que as respostas para estas perguntas também informem concepções subjacentes à organização e efetivação desta escola. 
Espaço Físico da Escola Pública Goiana de Tempo Integral

Quadro 7 - Ambientes Escolares que Carecem de Reformas

\begin{tabular}{|c|c|c|}
\hline Rede municipal de & Redes municipais & Rede estadual \\
\hline $\begin{array}{l}\left.1^{\circ}\right) \text { banheiros; } \\
\left.2^{\circ}\right) \text { refeitório; } \\
\left.3^{\circ}\right) \text { cozinha/salas de aula. } \\
\text { Outros: vestiários, sala de } \\
\text { jogos, de descanso e infor- } \\
\text { mática, rampas de acessi- } \\
\text { bilidade, sala de dança e } \\
\text { música, pátio, áreas verdes } \\
\text { e parques. }\end{array}$ & 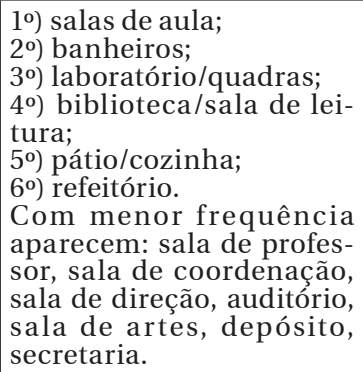 & $\begin{array}{l}\left.1^{\circ}\right) \text { banheiros; } \\
2^{\circ} \text { ) refeitório; } \\
3^{\circ} \text { ) cozinha/salas de aula. } \\
\text { Outros: madeiramento, } \\
\text { piso, forro, pintura, parte } \\
\text { hidráulica, fiação elétrica, } \\
\text { muro, fachada da escola, } \\
\text { janelas, aquisição de mo- } \\
\text { biliário para refeitório, } \\
\text { dentre outros. }\end{array}$ \\
\hline
\end{tabular}

Fonte: Barra et al. (2016).

O procedimento de interpretação dos dados do Quadro 7 combina análises que, ora cruzam os dados parciais, estabelecendo comparações entre as redes, ora os compara com dados dos quadros 6 e 7 , beneficiando-se assim de afinidades existentes entre os mesmos. Como se pode ver no Quadro 7, as reformas necessárias para as escolas com ampliação da jornada escolar no conjunto pesquisado (RME Goiânia, redes municipais, rede estadual) contemplam ambientes que não possuem associação privilegiada com o tema da ampliação da jornada escolar. Ou seja, não traduzem a especificidade deste formato de escola, entretanto são ambientes que ganham relevância ainda maior com o aumento da jornada. Aí se incluem salas de aula, banheiros, refeitório, sala de descanso, cozinhas, sala de jogos, laboratórios, biblioteca, quadras, dentre outros. Independem da organização temporal estendida da escola, mas especialmente necessários com esta. Com isso se nota que a pergunta que pretendia saber se os prédios escolares foram preparados para receber as experiências de ampliação da jornada escolar (Quadro 6), não apenas identificou que a média de $35 \%$ das escolas do estado não recebeu nenhum tipo de adaptação ou reforma, como muitas das reformas reclamadas (Quadro 7), dizem respeito à falta de manutenção devida para dependências fundamentais da escola, seja ela de funcionamento em tempo integral ou não.

É notável que, em se tratando de reformas necessárias (Quadro 7), a sala de aula concorra com a cozinha na terceira posição, tanto na capital como na rede estadual. Esses mesmos repartimentos do prédio escolar também carecem de reformas nas escolas das redes municipais, apesar de terem ordens distintas de prioridade. Quando a sala de aula e a cozinha aparecem como par, pode-se estar diante do indicativo da ordem da manutenção, que é a reforma que usualmente se deve realizar. Mas esta também pode ser uma pista a indicar que, ao mexer na jornada (tempo escolar) um novo desenho espacial se impõe e, se não há um prévio planejamento e organização do espaço físico, há uma perturbação na escala de prioridades que deve informar o desiderato da instituição escolar, o ensino.

1094 Educação \& Realidade, Porto Alegre, v. 42, n. 3, p. 1081-1101, jul./set. 2017. 
A maioria das escolas existentes (tempo regular) não possui refeitório (Quadro 8). Entendimento reforçado pelo quadro 7 no qual o refeitório aparece entre as últimas indicações dos ambientes que carecem de reforma. A baixa indicação de reforma deste ambiente (Quadro 7) é congruente com número de escolas que o possuem enquanto o status de ambiente a ser adaptado ou construído confere ao refeitório uma posição emblemática da precarização com a qual se institui a ampliação da jornada escolar que prevê a oferta de três refeições diárias. Saliente-se que nas três redes pesquisadas, o refeitório aparece nas três experiências de ampliação da jornada escolar, com todos os tipos de demanda: já sofreu reforma (Quadro 6), requer reforma/adaptação (Quadro 7), requer construção (Quadro 8). O exercício interpretativo em construção é o de que a demanda fisiológica dos corpos que povoam o espaço escolar rivaliza com a demanda intelectual do trabalho realizado na escola de tempo integral. Este argumento não pretende esvaziar o sentido pedagógico da refeição. Pretende apenas demonstrar que há paridade nas demandas dos diferentes ambientes físicos da escola.

Também tem notoriedade o modo expressivo com os quais aqueles ambientes que traduzem o manejo com o corpo aparecem nas listas de adaptados/reformados ou para serem construídos. Pátio. Quadra. Banheiro. Sala de repouso. Trata-se de uma equação que parece revelar que esses ambientes parecem tão ou mais reclamados que salas de aula ou laboratórios, ambientes que teriam uma relação mais explícita com o ensino. Reconhece-se que o conjunto desses ambientes cumpre relação direta com a dimensão pedagógica, mas se observa que, na lista das reformas necessárias prevalecem os ambientes que permitem maior mobilidade ao corpo. A precariedade da rede física das escolas é anterior à condição de ampliação da jornada escolar, o que a torna, no contexto atual, ainda mais merecedora de atenção.

Há ainda um quesito derivado do quadro acima (Quadro 7) que é dado pela dificuldade de identificar os espaços destinados às funções diretivas da escola. Somente um dos universos pesquisados mencionou salas de direção, coordenação pedagógica e sala de professores. Em estudo sobre a relação tempo e espaço na escola pública goiana da primeira fase do EF, foram encontradas situações nas quais os espaços destinados à direção escolar e funções correlatas foram subsumidos por outras funções, como por exemplo, algum arranjo espacial para assegurar a função de refeitório. Também salas de professores eram indicadas pelos próprios professores como espaços a serem transformados em espaços de usos outros (Barra, 2014). Enquanto sujeitos como o diretor, o coordenador pedagógico, o professor, parecem se abster de seus espaços no território escolar, a especificidade das suas funções parece se diluir no espectro ampliado das novas demandas limitadas por velhas limitações da realidade concreta. Mas é mais que isto. Numa perspectiva antropológica, alerta Edward T. Hall (1994, p. 64-65): “Possuir um território é um dos componentes essenciais da vida; quem não o possui encontra-se numa das situações mais precárias que é possível conceber".

Educação \& Realidade, Porto Alegre, v. 42, n. 3, p. 1081-1101, jul./set. 2017. 
Espaço Físico da Escola Pública Goiana de Tempo Integral

\section{Quadro 8 - Ambientes Indicados para Construção}

\begin{tabular}{|c|c|c|}
\hline $\begin{array}{l}\text { Rede municipal de } \\
\text { Goiânia }\end{array}$ & Redes municipais & Rede estadual \\
\hline $\begin{array}{l}\left.1^{\circ}\right) \text { refeitório; } \\
\left.2^{\circ}\right) \text { quadra coberta; } \\
3^{\circ} \text { ) sala de dança; } \\
4^{\circ} \text { ) sala de descanso; } \\
5^{\circ} \text { sala de aula; } \\
6^{\circ} \text { ) cozinha/banheiros/ } \\
\text { sala de direção. }\end{array}$ & 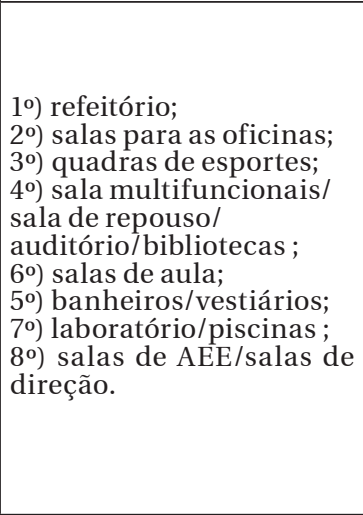 & 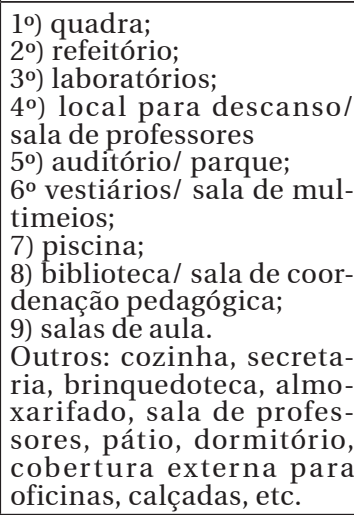 \\
\hline
\end{tabular}

Fonte: Barra et al. (2016).

Em conformidade com o Quadro 8, os ambientes que devem ser construídos nas três redes são, pela ordem, refeitório, quadra, salas para as oficinas, etc. Especialmente a capital e as redes municipais traduzem demandas realistas (ou básicas) de construção de ambientes para as novas funções escolares. Nota-se que a rede estadual tanto sinaliza contemplar-se com o mínimo que promove certa melhoria à condição de improviso: cobertura externa para as oficinas e calçadas, como oferece pistas que sintetizam a escola de tempo integral desejada pelos municípios. Para a escola sonhada requerem além de quadra, refeitório e laboratório, que se tenha local para descanso, sala de professores, auditório, parque, vestiários, sala de multimeios, piscina, biblioteca, sala de coordenação pedagógica, salas de aula.

Entre muitas similitudes e algumas diferenças vistas nos três universos pesquisados (Quadro 8), a rede estadual parece mais ousada na declaração dos ambientes a serem construídos nas dependências de suas escolas. Ou será o tamanho do seu sonho inversamente proporcional ao tamanho das suas limitações reais? Goiás é um estado de clima tropical com temperatura média anual de $23^{\circ} \mathrm{C}$, sendo que, na estação das chuvas (outubro a abril), as temperaturas são altas, principalmente nas regiões oeste e norte. Entre setembro e abril, as temperaturas podem chegar a até $39^{\circ}$. Apesar da alta temperatura e da baixa umidade a pesquisa identificou apenas um município que informou a construção de uma piscina, enquanto outro solicitava a construção de uma. Nenhum respondente aventou para a climatização das salas, o que tornaria o espaço-mor do ensino e da aprendizagem, um ambiente muito mais propício para sua finalidade. É a escola uma instituição modesta, opera no limite dado pelo mínimo. No conjunto da obra, a pesquisa mostra que o que se busca é a escola que consiga realizar as funções mais básicas. Estas podem ser traduzidas pelos seguintes equipamentos: sala de aula, quadra e banheiros. Somente um registro (Goiânia) apontava para a necessidade de manutenção de áreas verdes (jardins, hortas). Em 
alguns casos, estas áreas existem, embora não recebam os cuidados de que precisem. Ao mesmo tempo em que cumprem papel formativo tão importante quando a sala de aula já que educam para a fantasia, a beleza, a estética. Como adverte Frago e Escolano (1998, p. 89):

Por mais que se reduzam as condições de uma escola, por modestas que sejam suas exigências, jamais se deve renunciar a este elemento, tão importante, pelo menos, como a própria sala de aula, e cuja necessidade é, ao mesmo tempo higiênica e pedagógica.

\section{Considerações Finais}

A ampliação da jornada escolar na rede pública de Goiás se efetiva em diferentes modelos ou experiências, sendo ensejada pelo programa Mais Educação, cumpridor, em escalas estadual e municipal, da capilaridade da política de disseminação da escola de tempo integral no país. Engendra este movimento o amplo repertório de natureza normativa que pretende calçar de princípios as ações que visam aumentar o tempo de permanência da criança brasileira na escola, a partir de um argumento discursivo que subleva a condição do espaço físico escolar, suplantando-o por equipamentos públicos do seu entorno. Apesar de parcamente preparada para a ampliação da jornada, a escola pública goiana desenvolve a quase totalidade das novas funções no seu próprio reduto espacial. Entender este movimento centrípeto é parte daquilo que aqui se propôs. Estando em debate a escola de tempo integral, também se vislumbrou na pesquisa um grupo diminuto de respostas que apontavam por uma escola que tivesse a força de traduzir "oportunidades completas de vida” (Teixeira, 1977, p. 125-146), no sentido promover estudos, trabalho, vida social, recreação e jogos. Em tais respostas, parece atual o sonho de Anísio, um conjunto arquitetônico que contemplasse as atividades de instrução intelectual (escola classe, biblioteca), trabalho (oficinas), sociais (loja, clubes), educação física (ginásio, campo), artes (teatro, salas de música e dança). Nesta escola se formaria o homem em suas múltiplas dimensões, o estudioso, o operário, o artista, o esportista, “[...] o cidadão enfim, útil, inteligente, responsável e feliz" (Teixeira, 1977, p. 130-131). Por fim, cabe dizer que a grande maioria das experiências de ampliação da jornada escolar em realização no estado de Goiás se caracteriza por uma infraestrutura modesta, caracterizada por virtudes e vicissitudes. Trata-se de uma escola emblemática das novas demandas sociais impostas para a escola brasileira. Constitui parte importante do processo de democratização das oportunidades de formação científica e cultural de boa parte de crianças e adolescentes e possui vários desafios, dentre os quais, a melhoria da condição física de seu funcionamento, sendo este um aspecto de dimensão pedagógica das novas funções assumidas.

Recebido em 10 de dezembro de 2015 Aprovado em 06 de março de 2017

Educação \& Realidade, Porto Alegre, v. 42, n. 3, p. 1081-1101, jul./set. 2017. 
Espaço Físico da Escola Pública Goiana de Tempo Integral

\section{Notas}

1 Agência Financiadora: FAPEG.

2 A produção deste instrumento recebeu inspiração inicial de dois questionários, o primeiro foi empregado pela pesquisa publicada pelo MEC/SECAD (Brasília, 2009) e o segundo foi aquele empregado por Lígia Martha Coelho et al. (2012). Ao instrumento se acrescentou outros temas, dentre os quais, a infraestrutura. A sua versão final foi submetida à apreciação de equipe da Secretaria Estadual de Educação de Goiás (SEE/GO), REDE Municipal de Goiânia (RME Goiânia), tendo recebido ainda a contribuição da Profa. Dra. Lígia Martha Coelho.

$3 \mathrm{O}$ contato telefônico foi realizado em 2012 junto às secretarias municipais ou seus representantes nos 246 municípios goianos, sendo que houve efetivo contato com 231, já que em 15 casos não houve atendimento à ligação. A UNDIME (União dos Dirigentes Municipais de Goiânia) foi responsável pela cessão dos números telefônicos das redes municipais. O contato telefônico com a rede estadual foi feito junto às Subsecretarias Regionais de Educação (SRE), sendo os números cedidos pela SEE/GO. O contato com a RME Goiânia se deu junto à DEFIA (Divisão do Ensino Fundamental) e às respectivas Unidades Regionais de Educação (URE).

4 Cabe destacar que a magnitude dos dados da capital demandou procedimentos específicos de coleta de dados na rede municipal de educação de Goiânia. Na rede estadual os questionários foram, em geral, respondidos pelas subsecretarias de educação ou sob sua orientação. Já nas redes municipais (interior) as secretarias municipais de educação foram respondentes dos questionários. Por fim, a rede municipal da capital (Goiânia) respondeu aos questionários por meio das URE.

5 A partir do princípio do federalismo, que atinge o município na Constituição de 1988, da aprovação da Lei de Diretrizes e Bases da Educação Nacional (LDB 9394/96) e da Emenda Constitucional 14/96, que criou o Fundo de Manutenção e Desenvolvimento do Ensino Fundamental e Valorização do Magistério (Fundef), os governos locais tornaram-se os principais responsáveis pela oferta do ensino fundamental, através da municipalização do ensino. Ver mais em: Costa (2009).

6 A produção deste mapa se deu graças à colaboração do cartógrafo Silvio Braz de Sousa e mediação da Profa. Dra. Miriam Aparecida Bueno (IESA/UFG).

7 A Portaria Interministerial no 17, de 24 abril de 2007 (Brasil, 2007) criou o programa Mais Educação, responsável importante pela capilarização da ampliação da jornada escolar no país.

8 A tentativa de datar se confunde com o risco de se apontar para uma $p s e u d o g \hat{e}-$ nese. Tais autores fogem do exercício do desenvolvimento natural da instituição escolar para apreender a constituição da forma escolar moderna em cortes e continuidades inesperados. Entretanto a transição da gestão do ensino da igreja para o poder público é uma baliza relevante para o novo modelo escolar nascente.

9 Embora suas finalidades não fossem a formação primária específica, devem ser excepcionalidades no tema edificações escolares públicas goianas: o Liceu de Goiás (antiga capital Cidade de Goiás) e o Instituto Goiano de Educação (capital Goiânia). O segundo surgiu como um desmembramento do Liceu de Goiás (1929), passando a ser denominado IEG em 1947. Sua função primeira era a formação de professores primários.

1098 Educação \& Realidade, Porto Alegre, v. 42, n. 3, p. 1081-1101, jul./set. 2017. 
10 Táticas e estratégias - uso baseado em Michel de Certeau (1994).

11 Os números parciais correspondem ao conjunto estratificado das experiências identificadas no mesmo universo (rede estadual, municipais ou Goiânia). Na grande maioria, uma escola ou município desenvolve simultaneamente mais que uma experiência de ampliação da jornada escolar.

12 A Secretaria Municipal de Educação de Goiânia organiza a Rede Municipal de Educação em cinco Unidades Regionais de Educação (URE) que têm como finalidade o acompanhamento das ações pedagógicas das escolas. O critério de divisão das URE se baseia na localização geográfica da totalidade das escolas, hoje 163 unidades. Considerando a complexidade de Goiânia traduzida no número expressivo de unidades escolares, optou-se por delegar às URE a tarefa de responder ao questionário desta pesquisa. De tal modo que, o conjunto dos dados da rede municipal de educação de Goiânia se constitui a partir da totalização das amostras produzidas por cada uma das cinco URE.

13 No nível local se processam mudanças de relevo, como a transferência da capital, que deixa de ser Goiás Velho e passa a ser a cidade planejada Goiânia.

14 Cabe registrar, como demonstra Ana Cavaliere em alusão ao estudo de Vitor Paro que, em São Paulo, nos anos 1980, o PROFIC (Programa de Formação Integral da Criança) praticava a ideia de extensão do tempo escolar em diferentes espaços além da escola (Cavaliere, 2009).

\section{Referências}

BARRA, Valdeniza Maria Lopes da (Coord.); BRANDÃO, André Alcântara; BARBOSA, Rachel Evangelista; PAIVA, Neide Silva; PÓVOA, Maria de Fátima; MENEZES, Tereza Cristina de. Relatório Acadêmico de Pesquisa Educação Integral/ Integrada e(m) Tempo Integral nas Escolas Públicas de Goiás: um estudo sobre as experiências de ampliação da jornada escolar nos Anos Iniciais do Ensino Fundamental nas redes públicas de educação de Goiás. Goiás: UFG, 2016.

BARRA, Valdeniza Maria Lopes da. O Lugar da Escola Primária Goiana entre os Séculos XIX e XX. In: CASTRO, César Augusto; CASTELLANOS, Samuel Vellázquez (Org.). A Escola e seus Artefatos. São Luis: EDUFMA, 2013. P. 107-140.

BARRA, Valdeniza Maria Lopes da. Tempo e Espaço na Escola de Tempo Integral de Goiânia: traços de um projeto educacional contemporâneo. In: BARRA, Valdeniza Maria Lopes da (Org.). Educação: ensino, espaço e tempo na escola de tempo integral. Goiânia: CEGRAF/UFG, 2014. P. 115-142.

BRASIL. Constituição da República Federativa do Brasil de 1988. Nós, representantes do povo brasileiro, reunidos em Assembléia Nacional Constituinte para instituir um Estado Democrático, destinado a assegurar o exercício dos direitos sociais e individuais, a liberdade, a segurança, o bem-estar, o desenvolvimento, a igualdade e a justiça como valores supremos de uma sociedade fraterna, pluralista e sem preconceitos, fundada na harmonia social e comprometida, na ordem interna e internacional, com a solução pacífica das controvérsias, promulgamos, sob a proteção de Deus, a seguinte CONSTITUIÇÃO DA REPÚBLICA FEDERATIVA DO BRASIL. Diário Oficial da União, Brasília, 05 out. 1988. P. 1.

BRASIL. Ministério da Educação. Decreto no 7.083, de 27 de janeiro de 2010. Dispõe sobre o Programa Mais Educação. Diário Oficial da União, Brasília, 27 jan. 2010. P. 2.

BRASIL. Ministério da Educação. Lei no 10.172, de 9 de janeiro de 2001. Aprova o Plano Nacional de Educação e dá outras providências. Diário Oficial da União, Brasília, 10 jan. 2001. P. 1.

Educação \& Realidade, Porto Alegre, v. 42, n. 3, p. 1081-1101, jul./set. 2017. 
Espaço Físico da Escola Pública Goiana de Tempo Integral

BRASIL. Ministério da Educação. Lei no 13.005, 25 de junho de 2014. Aprova o Plano Nacional de Educação - PNE e dá outras providências. Diário Oficial da União, Brasília, 26 jun. 2014. P. 1.

BRASIL. Ministério da Educação. Portaria Interministerial no 17 de 24 de abril de 2007. Institui o Programa Mais Educação, que visa fomentar a educação integral de crianças, adolescentes e jovens, por meio do apoio a atividades sócio-educativas no contraturno escolar. Diário Oficial da União, Brasília, 26 abr. 2007.

BRASÍLIA. Educação Integral/Educação Integrada e(m) Tempo Integral: concepções e práticas na educação brasileira - mapeamento das experiências de jornada escolar ampliada no Brasil. Brasília: MEC; SECAD, 2009.

CAVALIERE, Ana Maria. Entre Disputas e Concepções: o horário integral nas escolas municipais do Rio de Janeiro. In: BARRA, Valdeniza Maria Lopes da (Org.). Educação: ensino, espaço e tempo na escola de tempo integral. Goiânia: CEGRAF/UFG, 2014. P. 169-185.

CAVALIERE, Ana Maria. Entre o Pioneirismo e o Impasse: a reforma paulista de 1920. Educação e Pesquisa, São Paulo, v. 29, n. 1, p. 27-44, jan./jun. 2003. Disponível em: <http://www.scielo.br/pdf/ep/v29n1/a03v29n1.pdf $\geq$. Acesso em: 03 out. 2016.

CAVALIERE, Ana Maria. Escola de Tempo Integral Versus Alunos em Tempo Integral. Em aberto, Brasília, v. 22, n. 80, p. 51-63, 2009.

CAVALIERE, Ana Maria. Escolas de Tempo Integral: uma ideia forte, uma experiência frágil. In: COELHO, Lígia Martha da Costa; CAVALIERE, Ana Maria (Org.). Educação Brasileira e(m) Tempo integral. Petrópolis: Vozes, 2002. P. 93-111.

CERTEAU, Michel de. A Invenção do Cotidiano. São Paulo: Vozes, 1994.

COELHO, Lígia Martha Coimbra da Costa; HORA, Dayse Martins; ROSA, Alessandra Victor do Nascimento; ALMEIDA, Érika, Christina Gomes de. Políticas Públicas de Ampliação da Jornada Escolar no Estado do Rio de Janeiro: de sujeitos e(m) formação e de sujeitos e(m) atuação (Relatório Acadêmico). Rio de Janeiro: UFRJ, 2012.

COSTA, Jean Mario. A Proposta de Municipalização do Ensino nos Anos 1990 e seus Impactos nas Relações entre Entes Federados. In: CUNHA, Maria Couto (Org.). Gestão Educacional nos Municípios: entraves e perspectivas. Salvador: EDUFBA, 2009. P. 119-163. Disponível em: <http://books.scielo.org/id/bxgqr/ pdf/cunha-9788523209025-04.pdf>. Acesso em: 03 out. 2014.

ELIAS, Norbert. Sobre o Tempo. Rio de Janeiro: Zahar Editores, 1998.

FARIA FILHO, Luciano Mendes de; VIDAL, Diana Gonçalves. Os Tempos e os Espaços Escolares no Processo de Institucionalização da Escola Primária no Brasil. Revista Brasileira de Educação, Campinas, p. 19-34, 2000.

FRAGO, António Viñao; ESCOLANO, Agustín. Currículo, Espaço e Subjetividade: a arquitetura como programa. Rio de Janeiro: DP\&A Editora, 1998.

GOIÁS. Escola de Tempo Integral: espaço público para a construção da cidadania (versão preliminar). Goiânia: SEE/GO, 2007.

HALL, Edward. A Linguagem Silenciosa. Lisboa: Relógios D’Água Editores, 1994.

MOLL, Jaqueline. A Agenda da Educação Integral: compromissos para sua consolidação como política pública. In: MOLL, Jaqueline (Org.). Caminhos da Educação Integral no Brasil: direito a outros tempos e espaços educativos. Porto Alegre: Penso, 2012. P. 129-146.

1100 Educação \& Realidade, Porto Alegre, v. 42, n. 3, p. 1081-1101, jul./set. 2017. 
NAGLE, Jorge. Educação e Sociedade na Primeira República. São Paulo: EPU; Rio de Janeiro: Fundação Nacional de Material Escolar, 1974.

SAVIANI, Dermeval. História das Ideias Pedagógicas no Brasil. Campinas: Autores Associados, 2008.

SEVERINO, Milca. Educação se Faz com Pessoas, Não com Prédios. (Entrevista). Jornal Opção, Goiânia, 11-17 fev. 2007. Disponível: <http://educacao.go.gov. $\mathrm{br} /$ portal/educacao/index.asp $>$. Acesso em: 12 maio 2009.

SILVA, Nancy Ribeiro de Araújo e. Tradição e Renovação Educacional em Goiás. Goiânia: Oriente, 1975.

TEIXEIRA, Anísio. Educação Não é Privilégio. Revista Atualidades Pedagógicas, São Paulo, v. 130, 1977.

VINCENT, Guy; LAHIRE, Bernard; THIN, Daniel. Sobre a Teoria da Forma Escolar. Educação em Revista, Belo Horizonte, n. 33, p. 7-47, 2001.

Valdeniza Lopes Barra é graduada em Pedagogia e realizou estudos de Mestrado e Doutorado em Educação pela Pontifícia Universidade Católica de São Paulo. Professora adjunta da Faculdade de Educação da Universidade Federal de Goiás, com atuação no Programa de Pós-Graduação em Educação e no curso de Pedagogia.

E-mail: dabarra@yahoo.com.br 